Portland State University

PDXScholar

\title{
From Exhaustion to Exhilaration: Assessing Librarian Job Satisfaction with Virtual Reference
}

\author{
Arthur Hendricks \\ Portland State University, hendricksa@pdx.edu \\ Sherry Buchanan \\ Portland State University, sherryb@pdx.edu
}

Follow this and additional works at: https://pdxscholar.library.pdx.edu/ulib_fac

Part of the Library and Information Science Commons

Let us know how access to this document benefits you.

\section{Citation Details}

Hendricks, Arthur and Buchanan, Sherry, "From Exhaustion to Exhilaration: Assessing Librarian Job Satisfaction with Virtual Reference" (2013). Library Faculty Publications and Presentations. 81. https://pdxscholar.library.pdx.edu/ulib_fac/81

This Post-Print is brought to you for free and open access. It has been accepted for inclusion in Library Faculty Publications and Presentations by an authorized administrator of PDXScholar. Please contact us if we can make this document more accessible: pdxscholar@pdx.edu. 
From exhaustion to exhilaration: assessing librarian job satisfaction with virtual reference

\author{
Arthur Hendricks, Reference Department \\ Sherry Buchanan, Library Technologies \\ Portland State University \\ Portland, Oregon
}

Originally published as:

Arthur Hendricks, Sherry Buchanan, (2013) "From exhaustion to exhilaration: assessing

librarian job satisfaction with virtual reference", Library Hi Tech, Vol. 31 Iss: 1, pp.42 - 63 http://dx.doi.org/10.1108/07378831311303921

This Article is brought to you for free and open access by the Portland State University Library at PDXScholar 
While much has been written about user satisfaction with virtual reference or chat services, only a very small body of literature focuses on librarian job satisfaction. For the most part, disruptive user behavior is not addressed in the literature. The purpose of this article is to analyze the results of a survey of librarian attitudes toward providing chat reference services and to suggest ways to improve job satisfaction.

\section{Background}

The state of Oregon has a chat service called L-net, which is staffed primarily by volunteers. It began as Answerland in April 2003, but the name was changed to L-net in Spring of 2004, and at the time of this writing, the group decided to change the name back to Answerland (2012). This service is supported in part by the Institute of Museum and Library Services through the Library Services and Technology Act, administered by the Oregon State Library. The program is managed at Multnomah County Library in Oregon. The premise for the service is that Oregon's libraries can serve our communities well by connecting Oregon citizens directly to reference librarians online. Collaboration ensures that we do this efficiently and effectively.

The original Answerland used Tutor.com's chat software. It was a web-based chat system that did not require any special software for the user. Any web browser would work, although the system worked best with Windows rather than Mac. There were two types of sessions, Basic and Interact. Interact allowed the librarian to actively push pages to the patron and click on links that the patron could follow. In Basic, the patron could only have a page sent - the librarian could not click on links or interact on the page with users. Unfortunately, only PCs could take advantage of the Interact feature and anyone using a Mac or an older PC could only be served in Basic. If the patron supplied an email address, a chat transcript would be emailed to the user.

In 2006, the service switched over to OCLC's QuestionPoint, which is also web-based software. QuestionPoint, before its last upgrade, looked very much like Tutor.com's software. The librarian simply logged onto a webpage and selected queues to monitor, picking up chats on a first come, first served basis. When patrons could not be served by their home libraries, other members of the cooperative could step in to provide chat service. The only drawback was that a librarian from another institution might not know the particulars of the user's home library and may not have access to the same databases. Unfortunately, QuestionPoint had the same weaknesses as Tutor.com in that Mac users got short shrift from the software. With the advent of QuestionPoint, the state switched from using a shared username to individual accounts that allowed each staff member's name and affiliation to be displayed. In 2009, the statewide chat service switched from QuestionPoint to Jive's Spark. Spark is a Java-based client that works very much like other chat applications, such as AOL's Instant Messenger. The software was originally designed to allow businesses to have chat available for customer service, but it was modified for library use. Spark is now used by Oregon chat librarians, and during evening hours, the service rolls over to staff at OCLC who use QuestionPoint.

\section{$\underline{\text { Literature Review }}$}

Articles about user satisfaction with library services abound, but the body of literature addressing librarian satisfaction is small. The literature focusing specifically on librarian satisfaction in the realm of virtual reference, also known as digital reference or chat, is even smaller. Kresh (2002/2003) surveyed Library of Congress librarians and some of these librarians "found the chat experience to be both exhilarating and mentally exhausting" (Kresh, 2002). 
Joe Janes offers the "first comprehensive look at reference librarians' experience and attitudes around digital reference" (Janes, 2002). Respondents "believed that digital reference, broadly understood, has made reference work more accessible, more interesting, and more challenging." According to Janes, respondents were well-trained; 95 percent received some formal Internet training. As we might guess, those who were more positive about virtual reference were more immersed in the chat setting. Janes says, "Experience, not surprisingly, is a powerful indicator of attitude and opinion. Those who had answered the most questions via digital reference also were most positive about it" (Janes, 2002). In addition to correlating experience and immersion with satisfaction, Janes also highlights the enigmatic issue that Kresh brings to light. To use Kresh's language, librarians are exhilarated about new electronic resources but also exhausted. Janes' respondents "reported seeing a direct correlation between the increase in electronic resources [in] their own job satisfaction, at the same time several expressed feelings of being overwhelmed by constant change" (Janes, 2002). Ideally, librarians can strike a balance between knowing all available sources and searching strategies and effectively answering questions in chat, or referring when needed. Developing and cultivating this balance may lead to more job satisfaction for chat librarians. Of note from Janes' study are what librarians deemed the best and worst questions: " the 'best' questions for digital reference include ready reference questions" and "the 'worst' questions are those of a personal or private nature, those from children, and 'research questions,' which received by far the highest negative rating" (Janes, 2002).

It should be mentioned that Janes along with Hill created another survey in 2002 (Janes \& Hill), but its methods were informal, based on a limited number of telephone interviews and responses to an email listserv posting. With regard to the findings, the respondents were broken down as follows: "seven represented public libraries, twelve academic, two government, and one corporate," and based on this small number of respondents, the authors were "unable to make grand inferences from our results or even generalized comments about librarians, reference, or digital reference practices" (Janes and Hill, 2002). Of note from this survey, however, is the fact that respondents "commented with some ambivalence" to the question about the reference interview, many saying "they are not sure how their services measure up to traditional services" and several mentioning their "discomfort" because of the "lack of a traditional reference interview" (Janes and Hill, 2002). There were conflicting reports that the "reference interview is definitely necessary, along with reports that it is somewhat passé," pointing to a disparity between "traditional ideals and actual reference practice" (Janes and Hill, 2002).

Hurst \& Shrimplin examine librarian attitudes toward virtual reference using Q methodology as a way to uncover points of view. The "analysis revealed three attitudinal typologies: Technophiles, Traditionalists, and Pragmatists" and this "analysis provides data on the actual range of feelings and attitudes about providing virtual reference services" (Hurst and Shrimplin, 2007). Another trend in the literature is the need for training. Hurst and Shrimplin reference Tenopir and Ennis who state that librarians "felt that they needed more instruction to be effective" (Hurst and Shrimplin, 2007). This theme is present throughout the body of literature we examined. Consistently in the body of literature, more training or instruction leads to more job satisfaction. With regard to virtual reference, according to Hurst and Shrimplin, "While some librarians have been largely positive about it since the beginning, others still bemoan the loss of the reference interview and traditional face-to-face reference service" (Hurst and Shrimplin, 2007). This trend toward longing for the traditional mode of reference service may be the cause behind some of the negativity we observe in responses about attitudes toward chat. Hurst and Shrimplin's study is goal-oriented toward improving service; the intent of their study is for information to be "used for practical purposes such as improving staffing decisions and utilizing staff 
more effectively, while at the same time improving morale and perhaps even increasing staff retention" (Hurst and Shrimplin, 2007). They reiterate our findings that "most of the research on virtual reference services has focused on the patron end and their level of satisfaction" (Hurst and Shrimplin, 2007). The results of the survey show that traditionalists "are performing a balancing act ... between their own opinions about virtual reference and the need to be a team player." Technophiles "may feel unduly constrained by those around them that do not share their enthusiasm for this latest piece of technology" (Hurst and Shrimplin, 2007). They point out that "playing to people's strengths is the ideal, but that can only be done once those strengths are known." (Hurst and Shrimplin, 2007). They mention future goals of examining attitudes within an organization to determine the "range of attitudes among colleagues" and then consider how technophiles, traditionalists, and pragmatists can move "towards an improved working environment and improved patron service (Hurst and Shrimplin, 2007). Knowing that there are "competing viewpoints toward virtual reference," we can consider building consensus and shared values, and "encourage administrators and librarians to work together to find the mix of roles and responsibilities that work best" (Hurst and Shrimplin, 2007).

Long and Steiner note that "librarian perceptions run the gamut" and comment that "while some have embraced the technology with wholehearted enthusiasm, some show total disinterest, and some display informed dislike" (Long and Steiner, 2007). These authors are primarily examining IM (where a username is required), as opposed to chat where no username is required. Having an IM name meets users at their point of need, whereas offering chat service may or may not be at their point of need. Long and Steiner note that "a comparison of responses based on age indicates that younger librarians are more likely to prefer IM as a mode of virtual reference than older librarians" (Long and Steiner, 2007). According to Long and Steiner, the "primary reason librarians favor IM is that they believe it has the potential to draw student interest" (Long and Steiner, 2007), again citing point of need. Of particular note about this study is the fact that 5 percent of respondents "feel strongly that IM should not be part of reference service" (Long and Steiner, 2007). It is this exasperation that may color librarian attitudes when staffing chat service.

Barbier and Ward note that the most challenging aspects of virtual reference are "when the software doesn't work properly or the numbers for accessing another institution's database won't work"; also "getting from a patron exactly what they want, while not seeing them and having to do it via chat" (Barbier and Ward, 2010). These themes are consistent in the literature, as was mentioned by Janes and Hill with regard to the reference interview as being a source of conflict. Barbier and Ward also identify the "most frequently occurring pitfalls to an exemplary chat" (Barbier and Ward, 2010):

1. Incomplete reference interview

2. Forgetting to check local information

\section{Technical Problems}

\section{Poor rapport between librarian and patron}

Barbier and Ward reference Bobrowsky, Beck and Grant (2005) who point to the notion that "Chat reference lacks the essential human interaction that makes face-to-face reference a complex and wonderful phenomenon" and assert that a "successful chat transaction depends on the librarian's ability to compensate for those missing cues" (Barbier and Ward, 2010). Barbier and Ward also note that "Chat is here to stay" and point out that "Pitfalls such as neophyte researchers, technical mine fields, 
incomplete questions, and a need for local information in a statewide service challenge librarians to adapt and develop techniques to maneuver these obstacles" (Barbier and Ward, 2010).

Radford and Connaway (2011), in their report, emphasize building relationships between librarians and users. It is mostly a collection of past research Radford has done, including interviews with patrons and librarians and analyzing chat transcripts. There is discussion on both sides of the virtual reference interview. Barriers for librarians are rude and impatient users, younger users whom the librarians felt wanted their homework done for them, and users who are unreceptive to suggestions.

\section{Methodology}

As can be seen from the literature review, there has been some discussion of librarian satisfaction, but not a great deal about librarian satisfaction with virtual reference. Therefore, we endeavored to survey the volunteers of Oregon's statewide chat service. The authors contacted L-net's coordinators to present a draft survey instrument and seek permission to survey the group. We conducted an online survey using Qualtrics and sent out a message to the volunteers through L-net's official email discussion list. Qualtrics not only collects data, it also allows one to analyze the data and create reports. The survey was also mentioned in the service's email newsletter as a reminder. L-net volunteers were given two months to answer the survey, which closed on December 1, 2011. The survey consisted of 29 questions (see Appendix 1). There are over 400 volunteers, but we only received 59 responses, resulting in a $29.5 \%$ return rate. It's not clear why the response rate was low. Also, the survey population was limited to just Oregon-based librarians, so the scope is limited to a particular population.

\section{Analysis of Results}

We began by asking the respondents to classify themselves as a type of librarian. More than half (51 percent) identified themselves as public $(n=30)$, followed by 36 percent academic $(n=21)$. This is not surprising since the majority of libraries participating in L-net are public. Seven percent were still attending library school $(n=4)$. Only one person self-identified as being unemployed. Another respondent self-identified as Library Assistant 3, while another listed Library Assistant.

Next, we asked respondents to select the size of the library that they work for. Most respondents were from larger libraries. See Table 1.

We then asked more specifically the size of population served by the respondent's library. Answers varied, from 200 to "over a million."

Next, we asked respondents how long they had been volunteering for L-net. The service began in April, 2003, so at the time of the survey eight years was the maximum length of time that someone could have been volunteering. The average number of years of service was seven. See Table 2.

We asked how many years of reference experience the respondents had. The results can be seen in Table 3. Nearly three quarters (72 percent) of respondents have over five years' experience.

Respondents were asked how many years of virtual reference experience that they had. The results can be seen in Table 4. As can be seen, the majority had less virtual reference experience than regular reference experience. 
Almost all respondents (93 percent) indicated that they had received virtual reference training directly from statewide coordinators. However, only 15 percent of respondents have an L-net Mentor. An L-net Mentor is someone who has been volunteering for L-net who advises newly trained volunteers. Mentors discuss chat strategies with mentees and also look over transcripts. In our study, Librarians in the 26-41 age range are more apt to have mentors $(p>0.05)$.

Most respondents (70 percent) work full-time (35 hours or more per week), while 26 percent work part-time, and only 4 percent are unemployed. Most respondents ( 87 percent) are female, while only 13 percent are male. With regard to age, 20 percent were in the 26-33 year old bracket, and 33 percent were in the 34-41 age bracket. The results can be seen in Table 5.

We asked for a list of all degrees and/or certificates that the respondents had earned. We assumed that those with library degrees would select MS, which 31 percent did. However, under Other, 31 percent wrote in MLS or MLIS. Another 27 percent indicated that they have a MA degree. Please see Table 6.

Of the respondents, 39 percent identified their programs as distance, while 61 percent did not. The fact that nearly $40 \%$ of respondents attended a distance program is interesting, and we can infer that their online experience readied them for field work as chat librarians. A high percentage (77.8 percent) of those who stated they enjoy answering L-net questions received their library degrees online $(p>0.05)$. We also asked in what year respondents had earned their library degree. The late nineties to mid 2000s seem to be when most library degrees were earned.

We asked what L-net shifts the respondents cover. The responses varied greatly. Some have fixed times; others are substitutes.

Respondents were asked to rate their reference skills in comparison to their peers. Most librarians ( 85 percent) rated themselves average, while 3.7 percent rated themselves below average, and 11.3 percent rated themselves above average.

Respondents were next asked if they enjoy answering chat questions. 77 percent said yes whereas 23 percent stated they do not. Nearly a quarter of our librarians said they did not enjoy answering chat questions. We wanted to know why.

Of those from age 42 to 57,41 percent said they do not enjoy answering questions, whereas of those from 26-41, only 10.7 percent do not enjoy answering chat questions. Older librarians are the most dissatisfied. We also correlated experience with chat satisfaction. Most respondents, 72 percent, had over five years of reference experience and 24 percent indicated they do not enjoy answering chat questions. Librarians with under a year of reference experience had higher dissatisfaction at 25 percent, whereas librarians with one to five years of experience had a lower percentage of dissatisfaction at 20 percent. This seems to indicate that those with less than one year reference experience and those with more than five years comprise the majority of the respondents who do not enjoy answering chat questions. The authors were surprised to learn that new librarians with under a year of reference experience enjoyed answering chat questions the least. The fact that librarians with more than five years reference experience had a higher rate of dissatisfaction than those with one to five years' experience seems to indicate burnout amongst more experienced librarians. It could also be because more experienced librarians are used to traditional reference exchanges where there are visual cues as opposed to chat, which is mediated by a computer screen. 
Respondents were next asked why they did or did not enjoy answering chat questions. About a third (34.69 percent) indicated that they enjoy answering chat questions due to the diversity of questions they receive. One respondent wrote, "In my day-to-day work, I do not get the opportunity to provide reference service to library users. I enjoy interacting with people and helping to answer their questions. The more challenging the question, the more fun it is to answer. Although, even the most simple question about how to renew a book is satisfying because I can walk away knowing I helped someone out."

A little over a quarter of respondents ( 26.53 percent) indicate they enjoy volunteering due to the satisfaction of helping and/or a sense of altruism. A typical response was, "I like the satisfaction of knowing that I helped someone. I like providing a service for free that people actually want/need to use. I get satisfaction from working with people and this is a great opportunity for me to do that."

Some respondents ( 22.45 percent) thought that chat can be a challenging form of reference in both positive and negative ways. A typical positive response was, "I enjoy the diversity of the questions asked. The reference interview is an interesting challenge." A negative response was, "I find it rather nerve-racking, actually. I enjoy helping one patron via chat, but I'm always apprehensive about helping multiple patrons."

About one fifth (20.41 percent) of respondents cited having to deal with children and/or homework questions as a reason they do not like staffing the chat service. One respondent wrote, "Kids are impatient and rude." Another wrote, "The teacher in me gets tired of kids being rude and wanting a quick fix for their homework rather than ways to answer their questions."

Please see Table 7 for a listing of the major themes the authors extracted from the responses.

Overall, the responses indicated that more training may increase positive job satisfaction, and particularly more guidance on whether to answer a question or to teach how the question should be addressed. Offering access to or training on more authoritative sources to librarians answering questions for other libraries may also help. Addressing the discomfort with answering kids' questions is in order. In line with observations noted in the literature review, librarians cited the lack of visual cues as challenging, and so training to address that may improve our services.

We next asked if the respondents had ever received written abuse from patrons during a chat. 76 percent indicated they had. We next asked what happened. Swearing was the number one complaint at 28 percent, followed by sexual comments and rude remarks which tied at 17 percent.

Please see Table 8.

One respondent wrote, "I have had several sexually explicit advances from patrons, cursing, and trying to spam the system." Another wrote, "1 ex.: Male patron (he identified himself as male) wanted help knowing how to service his wife sexually. I provided a couple of good sites on couples' sexual relationships, women's sexual needs, and so on. He insisted on knowing my own needs, preferences, experiences, etc. I tried to bring him back to serious answers from professional sources. I finally informed him that I was happy to help with factual info (see above) and if he persisted with his behavior I would disconnect. He straightened up somewhat then left. "

We next asked how the abuse made the respondents feel, and 26 percent reported feeling neutral, followed by 24 percent feeling their time had been wasted, closely followed by 18 percent 
feeling angry. One respondent wrote, "I didn't let it affect me. It's not my fault that they feel the need to act that way and I'm nice to them." Another wrote, "It is very difficult to be gracious during these exchanges, I feel angry that my time is being wasted, and that this service is used as an avenue for pranks. It used to bother me a great deal more, but after some time and experience, nothing shocks me." Another respondent wrote, "How would any woman feel? Disrespected, 'assaulted' in a way, used for his personal titillation." Perhaps we need a way to address our feelings after experiencing these undesired chats, such as an online forum for sharing our experiences. This might be a way for us to give positive feedback and suggestions to other librarians who have bad experiences and want support and advice. Perhaps we could develop best practices for answering questions, and providing guidance when we are concerned that our time is being wasted purposefully.

Our next question was in regard to how often respondents received prank chats, and 41 percent indicated less than once per month, followed by 33 percent indicating once per month. It would be interesting if future surveys would assess the frequency of service disruptions and pranks to analyze if our service receives more interruptions than others.

\section{See Table 9.}

We next asked respondents if they ever avoided answering a question because they thought it was a prank. Interestingly, it was a 50/50 split. We then asked them why they did that, 61 percent indicated that they treat every question as though they were serious. One respondent wrote, "Something that may sound like a prank could be a legitimate question. For example, what looks like a prank could be a patron with limited English skills. And I've been asked some pretty weird legitimate questions in my time at the reference desk."

Some of the respondents (17 percent) wrote that they could tell it was a prank: "At first, I clicked no -- but there have been a couple that you can tell from the question you can see in the incoming chat box that it's a prank. Usually sexual in nature. If it comes through a second time, I take it, and just use the L-net script about appropriate language or try (emphasis on try) to see if there's a reference question disguised."

A small number of respondents (11 percent) indicated that it was stressful or because the same patron appeared with the same question. One respondent wrote, "If I've disconnected with a patron who has been abusive, and their email address continues to pop up with another chat request, I will reject it." Another respondent wrote, "Why should I waste my time and possibly miss another patron who has a legitimate question?" Another respondent wrote, "It is stressful trying to professionally engage a person who seems to be joking." This response points to a possible solution, such as providing training specifically intended to address this type of situation. Statewide coordinators encourage librarians to take every question seriously.

See Table 10.

Respondents explained how they deal with pranks, with 41 percent who warn the patron and then disconnect, followed by 20 percent who simply warn, and 27 percent who treat it as a serious question. One respondent wrote, "I try very hard to follow the advice that I've been given--try to give the patron the benefit of the doubt, try to treat it like a 'reference question' to see if they'll turn into one. And actually, that has worked before. But I won't work with someone who is abusive." Another respondent wrote, "If it's brief, maybe just a bit of goading on the part of the patron, I'll give a warning 
("This is a reference chat room. That language won't be tolerated here"), but if they are downright graphic and rude, I'll either just end the session or tell them they've crossed a line and then exit. I don't think I need to explain how repeatedly calling someone something foul is bad form. They know it is."

Please see Table 11.

We then asked respondents to indicate on a Likert scale how comfortable they feel answering chat questions. Slightly over one third experienced some level of discomfort (8 percent were very uncomfortable; 10 percent were uncomfortable; 19 percent were slightly uncomfortable). - Please see Table 12.

We asked respondents to list the types of questions they feel comfortable answering. More than a quarter ( 28 percent) indicated they felt comfortable answering almost any questions, and another quarter (26 percent) stated they felt comfortable answering research/strategy-based questions. A small percentage (15 percent) indicated they felt comfortable answering factual questions. Another 15 percent indicated they felt comfortable with general reference questions and another 15 percent stated they were comfortable answering library policy questions. Fewer (11 percent) indicated they were comfortable with academic questions, and the same number (11 percent) indicated they were comfortable with reader's advisory questions. The same percentage (nine percent) felt comfortable answering homework help questions and helping patrons narrow their topics. Another nine percent stated that they were comfortable with Internet searches, and another nine percent indicated they were comfortable navigating another library's website and/or catalog. Six percent stated they were comfortable with searches dealing with their area of subject specialization, and finally four percent indicated they were comfortable with ready reference questions. See Table 13.

One respondent wrote, "Most of them ... especially if there is already a question formulated. I find it harder to tease the question out by chat. I am better face-to-face with a patron who is shuffling or indecisive." This comment points again to the lack of visual cues cited in the literature and observed in our survey responses as a significant factor in librarian's job satisfaction. If we can find a way to provide support for this specific issue as related to the chat mode, for example how librarians can better address questions without those visual cues through clearly identified best practices, we may be ahead of the game. Another respondent wrote, "Anything not a prank or abusive - reference questions. Why is L-net spending professionals' time on video games and other lame things?" Another wrote, "Any type! I love the challenging ones, the simple ones, whatever. As long as the patron is sincere, I enjoy trying to help them."

We next asked what questions respondents were uncomfortable answering. A very low percentage (10 percent) stated that there were no questions that made them uncomfortable. One third (33 percent) indicated they were uncomfortable with "Do my homework for me" requests. More than a quarter (28 percent) indicated they felt uncomfortable with math questions. Nearly one fifth (18 percent) of respondents stated they were uncomfortable with personal questions. Local library policy questions made 15 percent of respondents uncomfortable. Legal questions made 13 percent uncomfortable. Personal problems made 10 percent uncomfortable. Questions that are pranks also gained 10 percent. Five percent stated that class visits made them uncomfortable. See Table 14.

One respondent wrote, "questions about sex, some very academic questions, requests for personal advice (just 'uncomfortable' on all three of these -- sometimes they turn out fine or even great)." Another wrote, "questions from people asking for my personal opinion to support some idea or 
theory that they are collecting. I tell them I cannot respond since in L-net I represent a non-profit entity while at work, and like to keep the 2 separate." Another wrote, "Obviously, I don't enjoy the prank calls. I don't like it when patrons are obviously just trolling for homework answers - they say, 'Just give me the answer' instead of looking at the web sites and resources I send to them."

Finally, we asked if the respondents had anything else they wanted to say. One respondent replied, "I think L-net training is very poor. There are a lot of things we can do to help our librarians be better reference librarians through chat. We just have not defined our beliefs about it. Everyone is a bit wishy washey, I think. It is like having a manager or director of a library who never takes a stand about the kind of service we are to give...so the librarians each individually make up their own ideas about it and the service is erratic....are we providing entertainment? Are we providing quick info? Are we educators...etc."

Another respondent wrote, "I don't like the term abuse when it comes to L-net. I think each case is individual, and using this word to describe what happens in L-net isn't appropriate."

Someone else wrote, "I find it hard to perform chat while at the public reference desk. I prefer to do it at my desk while doing other projects. The ref desk is already too hectic without a "virtual layer" added to the mix." More training on multitasking and guiding principles about operational policies may lead to improved service.

Another wrote, "Need to make it clearer that they probably won't be getting someone at their library." Perhaps some of the widgets that roll over should be more appropriately labeled to let users know what happens when local staff is not online.

Another responded, "I love volunteering with L-net and I highly recommend the experience to other library school students who want to gain virtual reference experience in a well-supported environment. I think the encouraging and helpful nature of the L-net staff and the mentorship program have both helped ease my anxieties during my first month staffing the service."

\section{Analysis and Discussion}

We set out hoping to determine why chat is terrifying for some librarians, or why some librarians find it exhausting or are uncomfortable answering questions. Many respondents have several years of experience, training from statewide coordinators, and still there are nearly a quarter of respondents that are uncomfortable answering questions. What is the source of this discomfort? One obvious problem seems to be the anonymity of the service and the way chat can serve as an outlet for youth learning boundaries. As one respondent wrote, "While I enjoy L-net, I wish there was a way to block chronic pranksters. I've had the same kids pranking me every week and it gets a little old and takes me away from people who have legitimate questions." What many L-net volunteers don't seem to know is that questions that are marked as Prank do get flagged, and if an IP address gets noted enough, questions from it are not routed to the general queue, but instead answered by statewide coordinators. There is actually an algorithm in place that routes questions from these patrons whose questions are repeatedly marked as pranks. Occasionally, an abusive IP address is blocked. Aside from a few unruly kids and pranksters whose repeated pranks are ultimately blocked, we have a lot of serious questions and still nearly a quarter of respondents uncomfortable answering them. So how do we address that issue? 
The literature review and our survey responses point to some key factors that we can address. Support for librarians who have experienced what we may term verbal abuse may be a ready solution. We could create an area on our website that would serve as a forum, to which we could subscribe and share stories and suggestions about the questions that made us uncomfortable and best practices in responding to these questions (or the verbal abuse). Creating an open forum to talk about what makes us uncomfortable and how to address it may alleviate some of the isolation we feel in dealing with these pranks.

Additionally, we could develop best practices specific to the lack of visual cues. In the literature review and in our survey responses, we noticed time and again that librarians experience lower job satisfaction specifically as a result of their lack of visual cues in chat mode. With face to face reference, we can readily observe the patron's age, the nuances of facial expressions and body language that help us better answer their questions. In chat, we lack those visual cues. Are there ways to counterbalance this shortcoming? Consider if we developed best practices to ensure that we are doing a thorough reference interview, but quickly so that we don't "lose" our patrons. For example, say you received a question such as "What is the composition of Martian soil?" You may initially think that this would be a time-consuming question. In person, you can see if someone is shifting around, looking at the clock, needs to get to class, etc. In cases like this in chat, we don't know how fast the patron expects the answer. We can benefit from asking the patron, "Do you have some time for me to do some checking?" Knowing if the patron is in a hurry or has an hour can make all the difference in librarian job satisfaction. If the patron only has five minutes, then we can be honest and say, "This question may take a little longer to research; can we email you the information later?" Then we can set the question to follow up and focus on providing a better answer via email. Chat does not always mean that we have to hurry to answer a question. Being fast is probably helpful, but some questions take longer, and asking if the patron has time is one strategy that we can employ as a best practice. Developing more best practices to compensate for the loss of face to face reference may put librarians more at ease and increase job satisfaction.

Many respondents mentioned more training would help them with their discomfort. The literature review supports this idea. With so many sources, so many disciplines, with new sources and disciplines developing every day, it's no wonder that librarians feel pressure on the job. What if we developed a stronger mentor program? Would these librarians who feel discomfort become mentees? What other avenues could we take to provide more training? Of course, librarians should make every effort to attend the annual Oregon Virtual Reference Summit and other conferences or training sessions, where new sources and strategies are highlighted. In addition, both authors of this article have served as mentors, and we can provide some tips that helped our mentees.

There is a strategy of being ready to answer reference questions called "intentional reference." If we focus on being more mindful of our practice, we will feel more ready to answer questions. In practice, the authors recommend using some tools that help us deliver answers more quickly. Chat librarians may benefit from setting up their Internet browsers with multiple tab home pages, such as: Google Books, WorldCat, Occupational Outlook Handbook, Ask Alice, Scarleteen, homework or tutoring sites, Wikipedia, and any site that is regularly used. Intentional reference is about being ready to answer any question, and then being in the cycle of planning, acting, reflecting and revising your plan. So, if librarians start getting more questions about oral histories, perhaps add a new tab to the page list. In FireFox, in the Options menu, under General, there is an option to add multiple web pages to your tabbed home page list: 


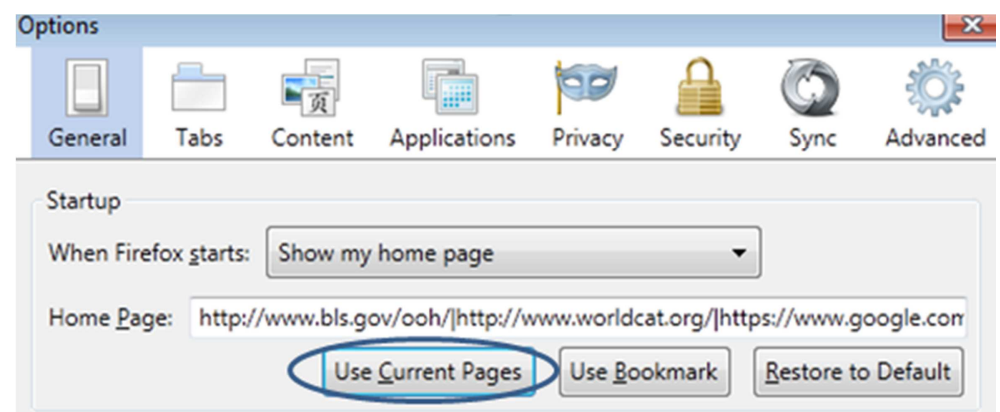

The "Use Current Pages" button functions to set open tabs as multiple home pages when the browser is launched. Note that hitting the home icon launches another set of homepages. Another way to be ready for any question is to use the Add to Search Bar Firefox Addon, which allows searching across multiple platforms by simply changing the drop-down selection, so that keywords are only typed once. Here is an example:

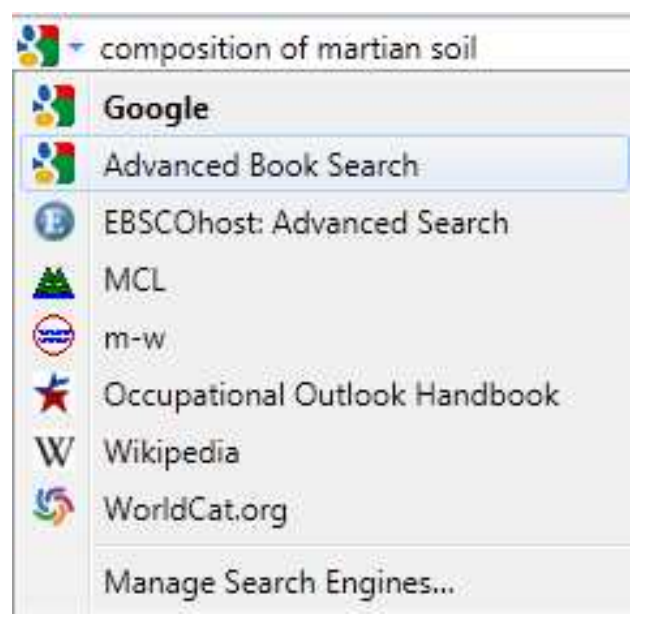

Having your known sources ready is a great way to feel more comfortable answering chat questions.

Another common issue with our service is academic librarians trying to answer kid's questions, and public librarians trying to answer college student's questions. The diversity of questions helps us stretch and grow as librarians, but as a group we should consider options to improve both our services and librarian satisfaction. Perhaps knowing that more kids are online in the afternoon right after school, we could ensure that librarians working those hours have special training in helping kids.

Another source of tension mentioned several times by our respondents is the struggle between just answering the question or teaching the patron how to answer his or her own question. In talking with L-net team leaders, just answering the question is okay. Many librarians responding to the survey expressed discomfort with just giving answers without describing how the information was found, but not feeling pressure to explain how answers were found could make chat more enjoyable. Patrons just want the answers. We can offer the answer, and then ask the patron if they want to know how we found it. That opens the dialogue, and if they don't want to know, that's fine. We've done our job and should be satisfied. Librarians can always refer to homework help sources such as tutor.com, available free through some public library websites, including the Multnomah County Library website. The tension between answering and teaching is common among librarians, but we can all agree that we should try to let go of what makes us uncomfortable. 
Finally, we should consider the challenges at the operational level. Staff who dislike answering reference questions should be free to work in other areas of the library where their job satisfaction would be higher. Managers can reassign those librarians if both parties agree that it would improve service and job satisfaction. Another suggestion that came from the survey is the concept of separating the reference desk from chat service, meaning librarians at the reference desk would not be trying to multitask to answer face to face reference questions as well as chat questions at the same time. This tension sets up librarians for lower job satisfaction since they may feel like someone is getting shortchanged their full attention.

As for dealing with disruptive patrons, the best policy seems to be treating each question seriously, and warning and ultimately disconnecting if the disruptive behavior continues. There's not much librarians can do about the anonymity of the Internet, but if we follow the rules, and try not to take it personally, chat should be less stressful.

\section{Conclusion}

In summary, the literature review, survey responses and inferences from qualitative data led us to some new ideas that may help librarians who feel uncomfortable. We offer several approaches to increase job satisfaction amongst chat librarians. An open forum could be established to share chat transcripts to help librarians deal with verbal abuse or pranksters. We could develop best practices for chat to compensate for a lack of visual cues. For example, common reference interview questions could be compiled to help chat librarians in their interactions. Librarians should seek more training, consider joining a mentorship program, and attend reference-specific conferences where new strategies and sources are revealed. More specialized training will aid librarians in answering a wider variety of questions. Librarians who practice intentional reference may be more comfortable answering chat questions. At an operational level, consider focusing staff where they receive the most job satisfaction and consider separating the reference desk from chat service. Managers might consider scheduling librarians with special training to monitor the queue in the afternoon when children are more likely to use the service. One should answer questions, but let go of the desire to explain how the answer was found. If some of these steps are taken, chat librarians might feel less exhausted and more exhilarated, and ideally the service will be better-staffed, and those staffing the service will be more satisfied with their jobs. 


\section{Appendix 1.}

Q1 What type of librarian are you?

- $\quad$ public

- $\quad$ academic

- special

- school

- $\quad$ still in library school

- other

Q2 What is the size of the library you work for?

- $\quad$ very small (population served under 5,000 )

- $\quad$ small (population served 5,000 - 9,999)

- $\quad$ medium $(10,000-24,999)$

- $\quad$ medium large $(25,000-74,999)$

- $\quad$ large $(75,000-150,000)$

- $\quad$ very large $(150,001+)$

- not applicable

Answer If What is the size of the library you work for? not applicable Is Not Selected

Q31 What size population does your library serve?

Q3 How long have you been a librarian for L-net?

Q4 How many years of reference experience do you have?
- None
- Under a year
- 1-3 years
- 3-5 years
- $\quad$ Over 5 years

Q5 How many years of virtual reference experience do you have?
- Under a year
- 1-3 years
- 3-5 years
- $\quad$ Over 5 years

6 Did you receive virtual reference training directly from L-net staff?
- $\quad$ Yes
- No

Q7 Do you have an L-net Mentor?

$$
\text { - Yes }
$$


- No

Q8 Are you currently employed?

- Working full-time (35 hours or more per week)

- Working part-time (less than 35 hours per week)

- $\quad$ Not employed

- $\quad$ Retired

Q9 What is your gender?

- $\quad$ Male

- Female

- $\quad$ other/declined

Q10 What is your age?

- $\quad 18-25$

- 26-33

- $\quad 34-41$

- $\quad 42-49$

- $\quad 50-57$

- $\quad 58-65$

- $66+$

- $\quad$ Old enough to volunteer for L-net

Q11 Please list all of your degrees and/or certificates:

$\begin{array}{ll}\text { - } & \text { BA } \\ \text { - } & \text { BS } \\ \text { - } & \text { MA } \\ \text { - } & \text { MA } \\ \text { - } & \text { PhD } \\ \text { - } & \text { Other } \\ \text { - } & \text { MEd }\end{array}$

Q12 If you are already a librarian, did you earn your library degree via a distance education program? If you are still a library science student, are you currently enrolled in a distance education library science program?

- Yes

- No

Q13 In what year did you get your Library degree? (if applicable)

Q14 What hours do you normally cover L-net?

Q15 How would you rate your reference skills in comparison to your peers? 


\begin{tabular}{|c|c|c|c|}
\hline & Below Average & Average & Above Average \\
\hline rate yourself & $\bullet$ & $\bullet$ & $\bullet$ \\
\hline
\end{tabular}

Q16 Do you enjoy answering L-net chat questions?
- $\quad$ Yes
- No

Q17 Why or why not?

Q18 Have you ever received verbal/written abuse from a patron during your L-net sessions?

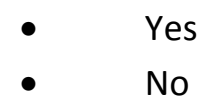

Answer If Have you ever received abuse from a patron during your L-... Yes Is Selected

Q19 If so, what happened?

Answer If Have you ever received abuse from a patron during your L-... Yes Is Selected

Q20 How did that make you feel?

Q21 How often do you receive prank chats?
- $\quad$ Never
- $\quad$ Less than Once a Month
- $\quad$ Once a Month
- 2-3 Times a Month
- Once a Week
- 2-3 Times a Week
- Daily

Q22 Do you ever avoid answering a question because you think it is a prank?
- $\quad$ Yes
- No

Q23 Why or why not?

Q24 How do you respond to abusive patrons and/or prank questions?

Q25 How comfortable do you feel when staffing L-net?
- very uncomfortable
- uncomfortable
- $\quad$ slightly uncomfortable
- neutral
- $\quad$ slightly comfortable
- comfortable 


\section{- $\quad$ very comfortable}

Q26 What types of questions do you feel comfortable answering?

Q27 What types of questions do you feel uncomfortable answering?

Q28 Are there any additional comments you'd like to make? 
Table 1: Size of Respondents' Libraries

\begin{tabular}{|c|c|c|c|}
\hline Answer & Table 1 & Response & $\%$ \\
\hline very small (population served under 5,000 ) & & 5 & $9 \%$ \\
\hline small (population served 5,000 - 9,999) & & 7 & $13 \%$ \\
\hline medium $(10,000$ - 24,999) & & 7 & $13 \%$ \\
\hline medium large $(25,000-74,999)$ & & 11 & $20 \%$ \\
\hline large $(75,000-150,000)$ & & 11 & $20 \%$ \\
\hline very large $(150,001+)$ & & 15 & $27 \%$ \\
\hline Total & & 56 & $100 \%$ \\
\hline
\end{tabular}

Table 2: Number of Years Volunteering For L-Net

\begin{tabular}{|l|l|c|c|}
\hline Answer & Table 2 & Response & $\%$ \\
\hline 1 month & & 2 & $4 \%$ \\
2 months & & 3 & $6 \%$ \\
3 months & 1 & $2 \%$ \\
6 months & 4 & $8 \%$ \\
1 year & & 9 & $17 \%$ \\
1.5 years & 2 & $4 \%$ \\
2 years & 6 & $11 \%$ \\
3 years & 9 & $17 \%$ \\
4 years & 7 & $13 \%$ \\
5 years & 3 & $6 \%$ \\
6 years & 1 & $2 \%$ \\
7 years & 3 & $6 \%$ \\
8 years & & 3 & $6 \%$ \\
\hline Total & 53 & $100 \%$ \\
\hline
\end{tabular}

Table 3: Years of Reference Experience

\begin{tabular}{|l|l|c|c|}
\hline Answer & Table 3 & Response & $\%$ \\
\hline None & & 1 & $2 \%$ \\
Under a year & & 4 & $7 \%$ \\
1-3 years & & 5 & $9 \%$ \\
3-5 years & 5 & $9 \%$ \\
Over 5 years & & 39 & $72 \%$ \\
\hline Total & 54 & $100 \%$ \\
\hline
\end{tabular}


Table 4: Years of Virtual Reference Experience

\begin{tabular}{|l|l|c|c|}
\hline Answer & Table 4 & Response & $\%$ \\
\hline Under a year & & 7 & $13 \%$ \\
1-3 years & & 19 & $35 \%$ \\
3-5 years & & 19 & $35 \%$ \\
Over 5 years & & 9 & $17 \%$ \\
\hline Total & & 54 & $100 \%$ \\
\hline
\end{tabular}

Table 5: Age of Respondents

\begin{tabular}{|l|l|c|c|}
\hline Answer & Table 5 & Response & $\%$ \\
\hline $18-25$ & & 1 & $2 \%$ \\
$26-33$ & & 11 & $20 \%$ \\
$34-41$ & & 18 & $33 \%$ \\
$42-49$ & 7 & $13 \%$ \\
$50-57$ & 10 & $19 \%$ \\
$58-65$ & 6 & $11 \%$ \\
$66+$ & 1 & $2 \%$ \\
Old enough to & & 0 & $0 \%$ \\
volunteer for L- & & & \\
net & & 54 & $100 \%$ \\
\hline Total & & & \\
\hline
\end{tabular}

Table 6: Degrees and/or Certificates Held By Respondents

\begin{tabular}{|c|l|l|c|c|}
\hline$\#$ & Answer & Table 6 & Response & $\%$ \\
\hline 1 & BA & & 40 & $77 \%$ \\
2 & BS & & 5 & $10 \%$ \\
3 & MA & 14 & $27 \%$ \\
4 & MS & 16 & $31 \%$ \\
5 & AA & & 4 & $8 \%$ \\
6 & PhD & & 0 & $0 \%$ \\
7 & Other & & 21 & $40 \%$ \\
8 & MEd & & 1 & $2 \%$ \\
11 & MFA & & 1 & $2 \%$ \\
\hline
\end{tabular}


Table 7: Why Respondents Did or Did Not Enjoy Answering Chat Questions

\begin{tabular}{|c|c|c|c|}
\hline Answer & Table 7 & Response & $\%$ \\
\hline $\begin{array}{l}\text { diversity of } \\
\text { questions }\end{array}$ & & 17 & $35 \%$ \\
\hline $\begin{array}{l}\text { Sometimes } \\
\text { (enjoyed } \\
\text { sometimes, } \\
\text { other times not) }\end{array}$ & & 5 & $10 \%$ \\
\hline $\begin{array}{l}\text { satisfaction of } \\
\text { helping/ altruism }\end{array}$ & & 13 & $27 \%$ \\
\hline $\begin{array}{l}\text { non-reference } \\
\text { questions }\end{array}$ & 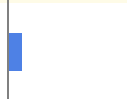 & 1 & $2 \%$ \\
\hline Rude & & 3 & $6 \%$ \\
\hline $\begin{array}{l}\text { challenging form } \\
\text { of reference }\end{array}$ & & 11 & $22 \%$ \\
\hline kids/homework & & 10 & $20 \%$ \\
\hline $\begin{array}{l}\text { lack of visual } \\
\text { cues }\end{array}$ & & 4 & $8 \%$ \\
\hline Pranks & 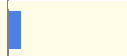 & 1 & $2 \%$ \\
\hline training needed & - & 3 & $6 \%$ \\
\hline
\end{tabular}

Table 8: Types of Abuse Received

\begin{tabular}{|l|l|c|c|}
\hline Answer & Table 8 & Response & $\%$ \\
\hline swearing & & 10 & $28 \%$ \\
inappropriate & & 3 & $8 \%$ \\
questions & & 5 & $14 \%$ \\
disconnected & & 6 & $17 \%$ \\
sexual comments & & 2 & $6 \%$ \\
insults & & 4 & $11 \%$ \\
pranks & & 6 & $17 \%$ \\
rude & & 5 & $14 \%$ \\
\hline kids & & & \\
\hline
\end{tabular}


Table 9: Frequency of Prank Chats

\begin{tabular}{|l|c|c|c|}
\hline Answer & Table 9 & Response & $\%$ \\
\hline Never & & 3 & $6 \%$ \\
Less than Once a Month & & 21 & $41 \%$ \\
Once a Month & 17 & $33 \%$ \\
2-3 Times a Month & 5 & $10 \%$ \\
Once a Week & 4 & $8 \%$ \\
2-3 Times a Week & 1 & $2 \%$ \\
Daily & 0 & $0 \%$ \\
\hline Total & & 51 & $100 \%$ \\
\hline
\end{tabular}

Table 10: Reasons for Not Taking a Chat

\begin{tabular}{|l|c|c|c|}
\hline Answer & Table 10 & Response & $\%$ \\
\hline treat as serious & & 28 & $61 \%$ \\
don't want to waste time & 4 & $9 \%$ \\
return patron/ repeated question & 5 & $11 \%$ \\
stressful & 5 & $11 \%$ \\
you can tell it's a prank & 8 & $17 \%$ \\
\hline
\end{tabular}

Table 11: How Respondents Deal With Pranks

\begin{tabular}{|l|l|c|c|}
\hline Answer & Table 11 & Response & $\%$ \\
\hline disconnect & & 7 & $16 \%$ \\
warn then disconnect & 18 & $41 \%$ \\
warn & & 9 & $20 \%$ \\
no pranks yet & 1 & $2 \%$ \\
humor & 2 & $5 \%$ \\
treat as a serious question & 12 & $27 \%$ \\
\hline
\end{tabular}


Table 12: Comfort Level Answering Chat Questions

\begin{tabular}{|c|c|c|c|c|}
\hline \# & Answer & Table 12 & Response & $\%$ \\
\hline 1 & $\begin{array}{l}\text { very } \\
\text { uncomfortable }\end{array}$ & & 4 & $8 \%$ \\
\hline 4 & neutral & & 4 & $8 \%$ \\
\hline 2 & uncomfortable & & 5 & $10 \%$ \\
\hline 5 & $\begin{array}{l}\text { slightly } \\
\text { comfortable }\end{array}$ & & 7 & $13 \%$ \\
\hline 7 & very comfortable & & 8 & $15 \%$ \\
\hline 3 & $\begin{array}{l}\text { slightly } \\
\text { uncomfortable }\end{array}$ & & 10 & $19 \%$ \\
\hline \multirow[t]{2}{*}{6} & comfortable & & 14 & $27 \%$ \\
\hline & Total & & 52 & $100 \%$ \\
\hline
\end{tabular}

Table 13: Types of Questions Respondents Feel Comfortable Answering

\begin{tabular}{|c|c|c|c|c|}
\hline$\#$ & Answer & Table 13 & Response & $\%$ \\
\hline 2 & anything & & 13 & $28 \%$ \\
\hline 7 & $\begin{array}{l}\text { research/ } \\
\text { strategy }\end{array}$ & & 12 & $26 \%$ \\
\hline 3 & factual & & 7 & $15 \%$ \\
\hline 8 & library policies & & 7 & $15 \%$ \\
\hline 4 & $\begin{array}{l}\text { reference } \\
\text { questions/ } \\
\text { finding known } \\
\text { items }\end{array}$ & & 7 & $15 \%$ \\
\hline 1 & academic & & 5 & $11 \%$ \\
\hline 6 & reader's advisory & & 5 & $11 \%$ \\
\hline 12 & Internet & & 4 & $9 \%$ \\
\hline 13 & $\begin{array}{l}\text { navigating } \\
\text { another library's } \\
\text { site/ catalog }\end{array}$ & & 4 & $9 \%$ \\
\hline 11 & narrow topic & & 4 & $9 \%$ \\
\hline 9 & homework help & & 4 & $9 \%$ \\
\hline 10 & $\begin{array}{l}\text { area of subject } \\
\text { specialization }\end{array}$ & & 3 & $6 \%$ \\
\hline 5 & ready reference & 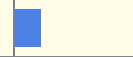 & 2 & $4 \%$ \\
\hline
\end{tabular}


Table 14: Questions Respondents Were Uncomfortable Answering

\begin{tabular}{|c|c|c|c|c|}
\hline$\#$ & Answer & Table 14 & Response & $\%$ \\
\hline 1 & $\begin{array}{l}\text { do my } \\
\text { homework }\end{array}$ & & 13 & $33 \%$ \\
\hline 2 & math & & 11 & $28 \%$ \\
\hline 9 & personal & & 7 & $18 \%$ \\
\hline 7 & $\begin{array}{l}\text { local library } \\
\text { policy questions }\end{array}$ & & 6 & $15 \%$ \\
\hline 3 & legal & & 5 & $13 \%$ \\
\hline 12 & $\begin{array}{l}\text { questions that } \\
\text { are pranks }\end{array}$ & & 4 & $10 \%$ \\
\hline 6 & $\begin{array}{l}\text { personal } \\
\text { problems }\end{array}$ & & 4 & $10 \%$ \\
\hline 5 & none & & 4 & $10 \%$ \\
\hline 11 & class visit & & 2 & $5 \%$ \\
\hline 4 & statistics & 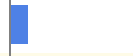 & 1 & $3 \%$ \\
\hline 8 & humanities & ] & 1 & $3 \%$ \\
\hline
\end{tabular}




\section{$\underline{\text { References }}$}

Barbier, P. and Ward, J. (2010). "Best practices in chat reference used by Florida's Ask a Librarian virtual reference librarians", in The Reference Librarian, Vol. 51, pp. 53-68.

Connaway, L. and Radford, M. (2011). "Seeking Synchronicity: Revelations and Recommendations for Virtual Reference. Dublin, OH: OCLC Research. http://www.oclc.org/reports/synchronicity/default.htm.

Hurst, S. and Shrimplin, A. (2007). "A virtual standoff - Using Q methodology to analyze virtual reference", in Evidence Based Library and Information Practice, Vol. 2 No. 4, pp. 4-21.

Janes, J. (2002). "Digital Reference: Reference Librarians' Experiences and Attitudes", in Journal of the American Society for Information Science and Technology, Vol. 53 No. 7, pp. 549-566.

Janes, J. and Hill, C. (2002). "Finger on the Pulse: Librarians Describe Evolving Reference Practice in an Increasingly Digital World" in Reference \& User Services Quarterly, Vol. 42, pp. 54-65.

Kresh, D. (2002/2003). "Virtually Yours: Thoughts on Where We Have Been and Where We Are Going with Virtual Reference Services in Libraries", in The Reference Librarian, Vol. 79/80, pp. 19-34.

Long, C. and Steiner, S. (2007). "What are we afraid of? A survey of librarian opinions and misconceptions regarding instant messenger", in The Reference Librarian, Vol. 47 No. 1, pp. 31-50. 